\title{
X-Ray Mapping Investigations of Salt Migration in Seeds through use of Window and Windowless Silicon Drift Detectors
}

\author{
Richard Wuhrer ${ }^{1}$, Lydia Guja ${ }^{2}$, David Merritt ${ }^{3}$ and Ken Moran ${ }^{4}$ \\ ${ }^{1}$ Advanced Materials Characterisation Facility, University of Western Sydney, Australia. \\ 2 Australian National Botanic Gardens and CSIRO Plant Industry, Canberra, Australia. \\ ${ }^{3}$ Kings Park and Botanic Garden and School of Plant Biology, University of Western Australia, \\ Australia. \\ ${ }^{4}$ Moran Scientific, Goulburn, NSW, Australia.
}

\section{Introduction}

The salt avoidance or tolerance mechanisms of adult plants are reasonably well understood. However, this is not the case for seeds, particularly during the transition from imbibition (water uptake) to germination. Common Australian coastal plants have different salt responses at germination [1-2]. Seeds of Ficinia nodosa are salt tolerant, survive exposure to extremely high $\mathrm{NaCl}$, and are able to recover and germinate if salinity is alleviated. Conversely, seeds of Spyridium globulosum are salt-sensitive during germination and experience ion toxicity, which significantly reduces seed germination. In light of these differing salt responses, this study sets out to determine 1) if seeds imbibe $\mathrm{NaCl}, 2$ ) if salt is 'stored' in particular seed tissues, and 3) during which phase of imbibition salt is taken up. This paper will present the use of X-ray mapping (XRM) and XRM post processing techniques (scatter diagram generation, pseudo colouring, Quantitative XRM (QXRM) and ratio mapping) to obtain more information about salt migration in seeds. Results from window and windowless silicon drift detectors (SDD's) will also be presented.

\section{Methods}

Seeds were exposed to various $\mathrm{NaCl}$ solutions then rinsed in iso-osmotic polyethylene glycol 8000 (PEG) to remove external salt without altering the osmotic balance of the seed. Seeds were cut longitudinally using a scalpel or double-edged razor blade to obtain a section. One seed half was mounted with the embryo facing upwards on a carbon-taped Al stub and carbon coated. X-ray maps were collected on a Jeol 733 EM Probe and Jeol 35CF scanning electron microscope (SEM) with a Moran Scientific EDS microanalysis system and post processing imaging software [3-4]. The Jeol 733 EM Probe has Amptek window and windowless silicon drift detectors (SDD's).

\section{Results and Discussion}

Fig. 1 shows the X-ray mapping results for F. nodosa (a) and S. globulosum (b) seeds after exposure to high salinity ( $\geq 500 \mathrm{mM}$ ). The $F$. nodosa seeds reveal that no $\mathrm{Na}$ was imbibed and was only present around the outside of the seed. However, some $\mathrm{Cl}$ did enter the internal seed tissues. The higher the $\mathrm{NaCl}$ concentration seeds were exposed to, the greater the amount of $\mathrm{Cl}$ in the seed and the greater the area occupied by $\mathrm{Cl}$, with some indication of compartmentalisation within the endosperm. The salt tolerance of seeds of this species at germination is likely due to the exclusion of sodium from the seed during imbibition. In contrast, $S$. globulosum imbibed $\mathrm{Na}$ (Fig.1b) and the internal and external $\mathrm{Na}$ concentrations were positively correlated. $\mathrm{Na}$ was accumulated in the embryo along with $\mathrm{Cl}$. $\mathrm{Cl}$ was particularly concentrated around the radicle and hypocotyl. $\mathrm{Na}$ and $\mathrm{Cl}$ concentrations within the endosperm also increased. This accumulation of $\mathrm{Na}$ and $\mathrm{Cl}$ during imbibition results in ion toxicity of $S$. globulosum seeds after exposure to high salt concentrations. 


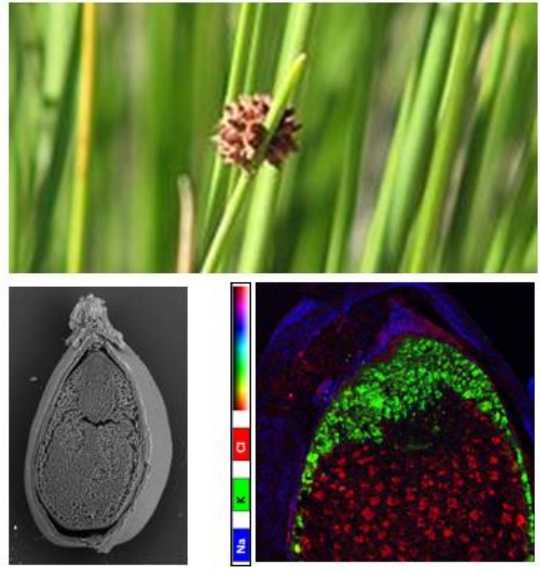

a.
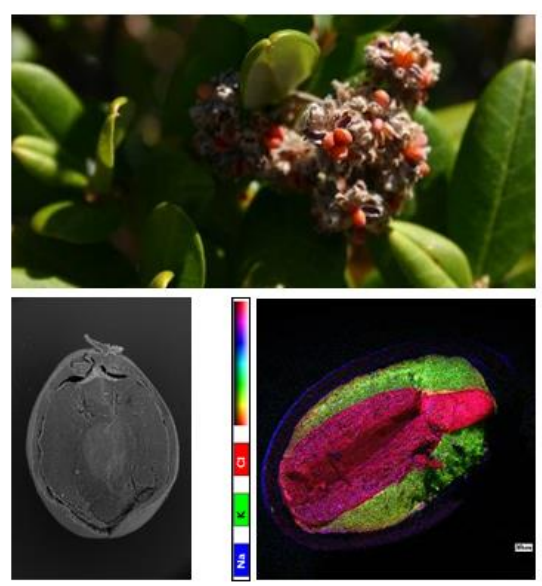

b.

Fig. 1: a) Knotted Club Rush ( $F$. nodosa), cross section of seed and pseudo coloured map indicating only $\mathrm{Cl}$ migration in the embryo b) Basket Bush (S. globulosum), cross-section of seed and pseudo coloured map indicating both $\mathrm{Na}$ and $\mathrm{Cl}$ distributed throughout the seed and concentrated in the embryo, which is where active growth occurs [modified from 2].

\section{References}

1. L.K.,Guja, D.J., Merritt, \& K.W., Dixon, (2010). Buoyancy, salt tolerance and germination of coastal seeds: implications for oceanic hydrochorous dispersal. Functional Plant Biology 37, 1175-1186.

2. L.K., Guja, R. Wuhrer, K. Moran, K. Dixon, G. Wardell-Johnson, D. Merritt, 2013, "Full spectrum X-ray mapping reveals differential localization of salt in germinating seeds of differing salt tolerance", Botanical Journal of the Linnean Society, vol 173, no 1, pp 129-142.

3. Moran, K. \& Wuhrer, R. (2006a). Quantitative bulk and trace element X-ray mapping using multiple detectors. Microchimica Acta 155(1-2), 59-66.

4. Moran, K. \& Wuhrer, R. (2006b). X-ray mapping and interpretation of scatter diagrams. Microchimica Acta 155(1-2), 209-217. 